Universidad de Lima

Facultad de Psicología

Carrera de Psicología

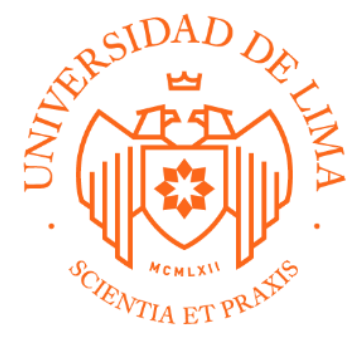

\title{
PROGRAMA DE CAPACITACION PARA DOCENTES EN ATENCIÓN A LA DIVERSIDAD A ALUMNOS CON TDAH
}

Trabajo de suficiencia profesional para optar el título profesional de licenciado en Psicología

Heidi Joany Noriega Solari de Ortiz

20041913

\author{
Asesor \\ Luis Alberto Esaine Suárez
}

Lima - Perú

Marzo del 2020 


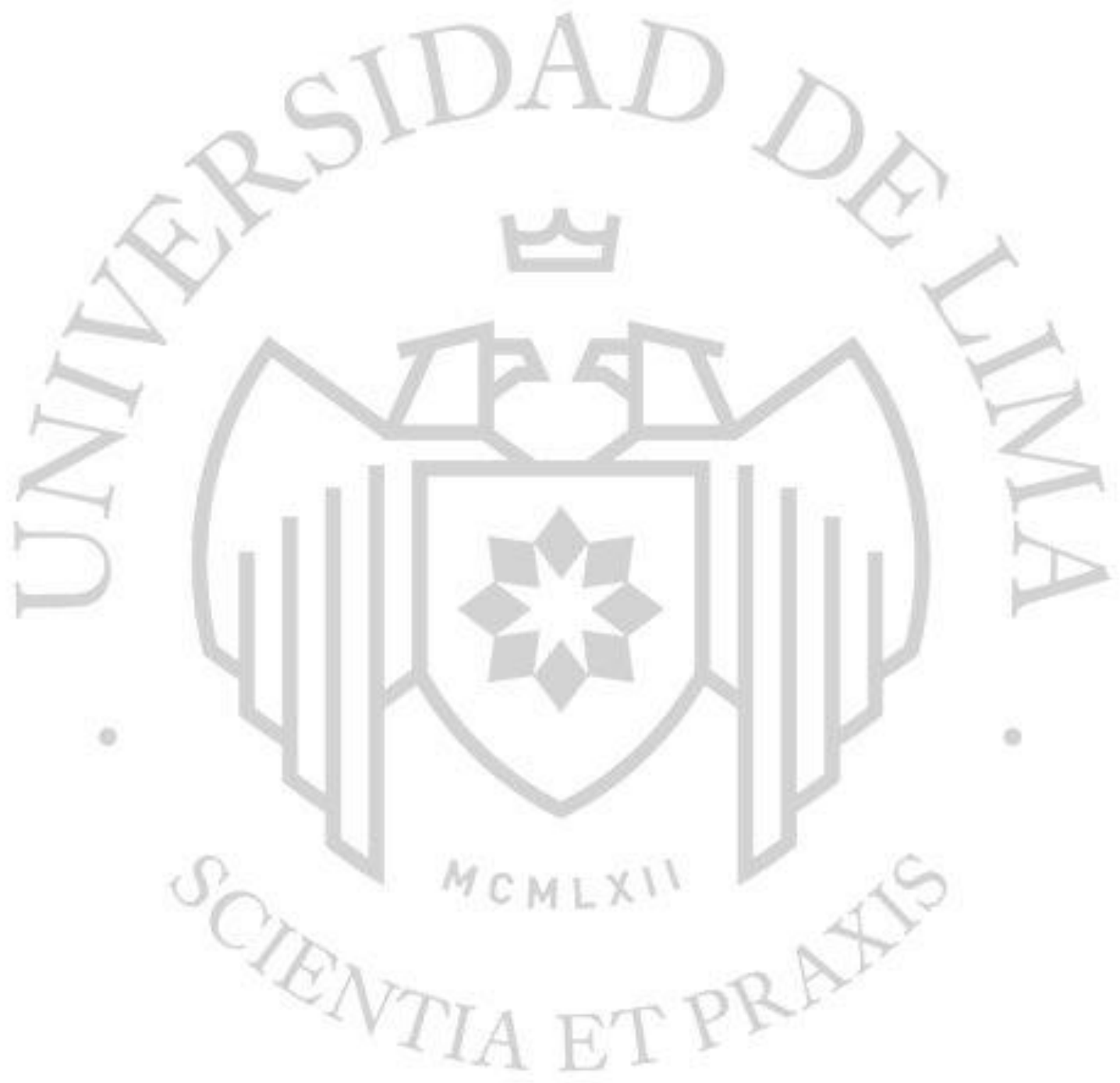




\section{TEACHER TRAINING PROGRAM IN}

ATTENTION TO DIVERSITY FOR STUDENTS WITH ADHD 


\section{RESUMEN}

Actualmente, los docentes necesitan capacitarse para atender la diversidad del alumnado y más aún si se trata de estudiantes con TDAH, el trastorno más presente en edad escolar (Valda, Suñagua, Coaquira, 2018) y que frecuentemente está ligado a bajo rendimiento académico y problemas conductuales. Este programa estuvo dirigido a 53 tutores de una institución pública de Lima Metropolitana con la finalidad de concientizarlos en atención a la diversidad de alumnos con TDAH, a través del conocimiento de las definiciones, la selección de estrategias metodológicas y el contraste entre la metodología tradicional y la del modelo de atención a la diversidad. El programa consta de tres etapas, la primera de conocimientos basada en la teoría de Barkley sobre TDAH, la segunda, de manejo de estrategias escolares basadas en las propuestas por la Asociación Peruana de Déficit de Atención y una última etapa de comparación entre la metodología tradicional y la de atención a la diversidad. Se realizó además una encuesta de entrada y de salida para corroborar la efectividad del programa, obteniendo resultados positivos en el aprendizaje de los tutores, por lo cual se infiere que cuentan con la capacidad de implementar estrategias para atender a la diversidad de los alumnos con TDAH.

Palabras clave: Diversidad/ Atención a la Diversidad/ Capacitación/ TDAH 


\begin{abstract}
Currently, teachers need to be trained to address the diversity of students and even more so if they are students with ADHD, the most present disorder in school age (Valda, Suñagua, Coaquira, 2018) and that is often linked to poor academic performance and behavioral problems. This program was aimed at 53 tutors of a public institution in Lima Metropolitana with the purpose of raising awareness in attention to the diversity of students with ADHD, through knowledge of the definitions, the selection of methodological strategies and the contrast between the traditional methodology and that of the model of attention to diversity. The program consists of three stages, the first of knowledge based on Barkley's theory of ADHD, the second, of management of school strategies based on those proposed by the Peruvian Association of Attention Deficit and a final stage of comparison between the traditional methodology and the attention to diversity. An entry and exit survey was also carried out to corroborate the effectiveness of the program, obtaining positive results in the learning of the tutors, so it is inferred that they have the ability to implement strategies to address the diversity of students with ADHD .
\end{abstract}

Keywords: Diversity; Attention to Diversity; Training; ADHD 


\section{TABLA DE CONTENIDO}

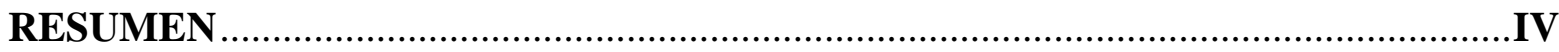

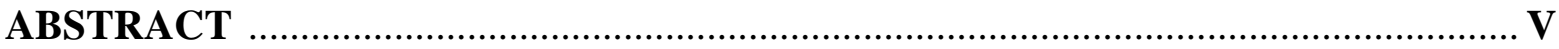

CAPÍTULO I: CONTEXTUALIZACIÓN DE LA PROBLEMÁTICA ......................... 1

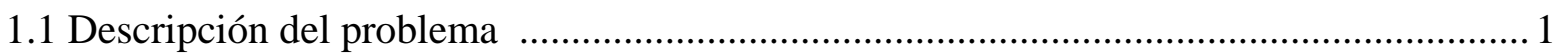

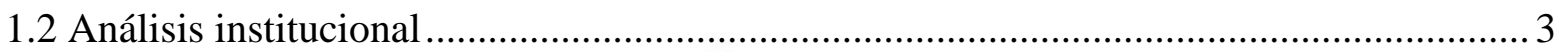

CAPÍTULO II: MARCO TEÓRICO Y ANTECEDENTES ......................................5

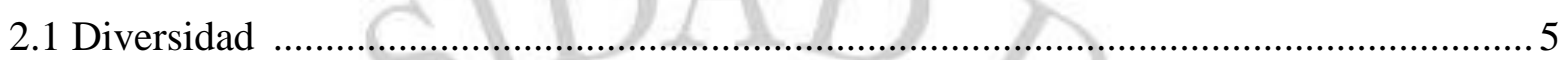

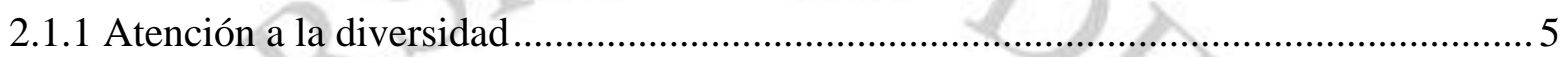

2.2 Trastorno por déficit de atención e hiperactividad ..................................................... 6

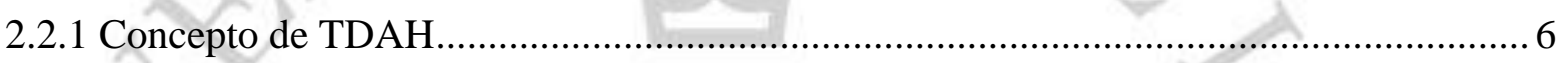

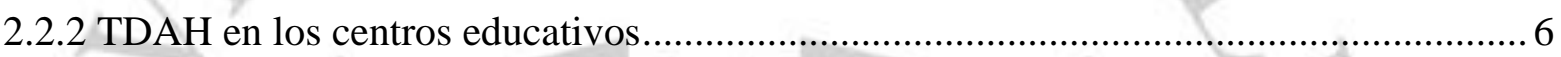

2.2.3. Modelo de dificultades para la inhibición de Barkley s ............................................. 7

CAPÍTULO III: OBJETIVOS GENERAL Y ESPECÍFICOS ...................................

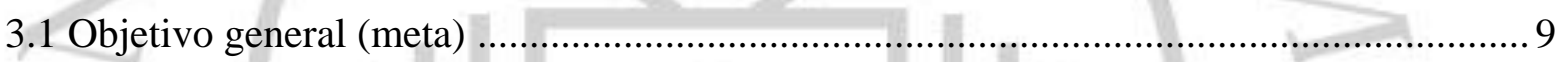

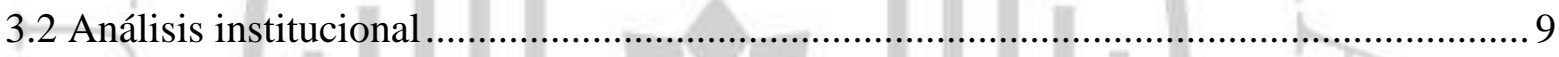

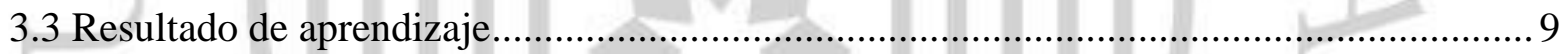

CAPÍTULO IV: METODOLOGÍA DE LA EVALUACIÓN E INTERVENCION .......10

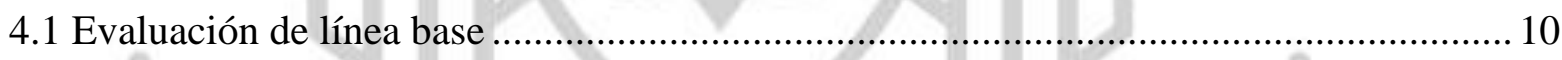

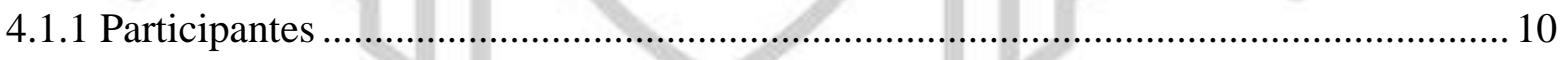

4.1.2 Técnicas y/o instrumentos de evaluación/ diagnóstico .............................................. 10

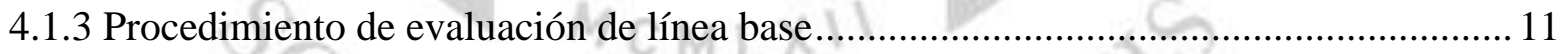

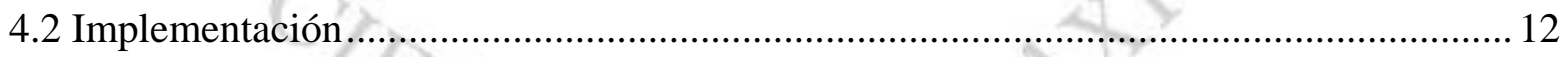

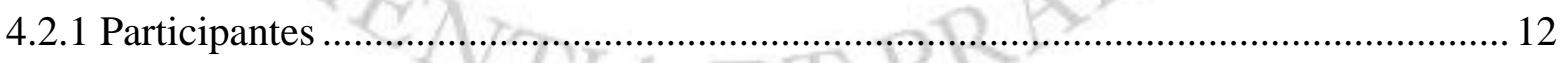

4.2.2. Instrumentos o herramientas de implementación/ intervención................................. 12

4.2.3 Procedimiento de implementación ....................................................................... 13

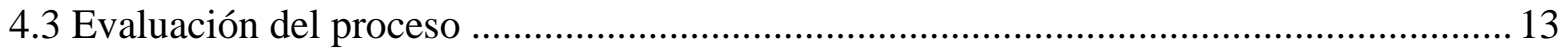

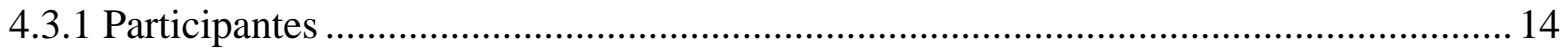

4.3.2. Técnicas y/o Instrumentos de evaluación/diagnóstico ............................................. 14

4.3.3 Procedimiento de evaluación del proceso ............................................................ 14

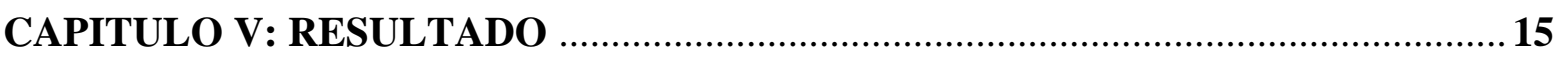

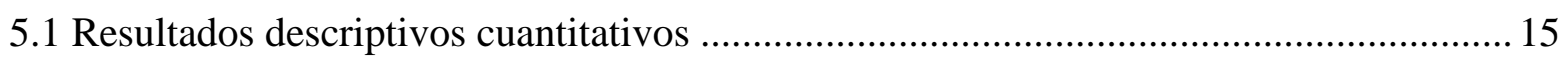


5.2 Resultados interpretativos 17

CONCLUSIONES 20

RECOMENDACIONES 21

REFERENCIAS 22

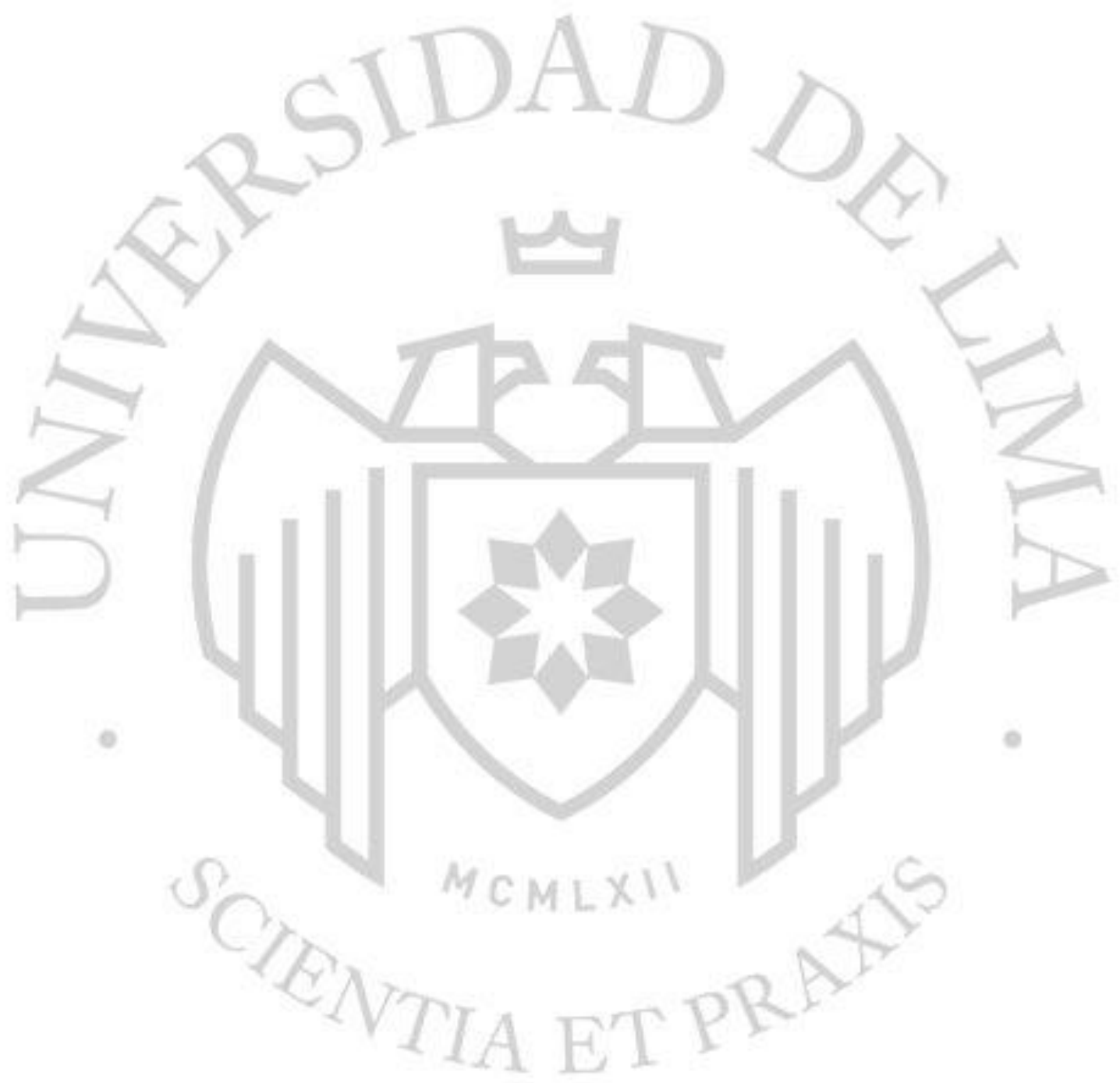




\section{ÍNDICE DE TABLAS}

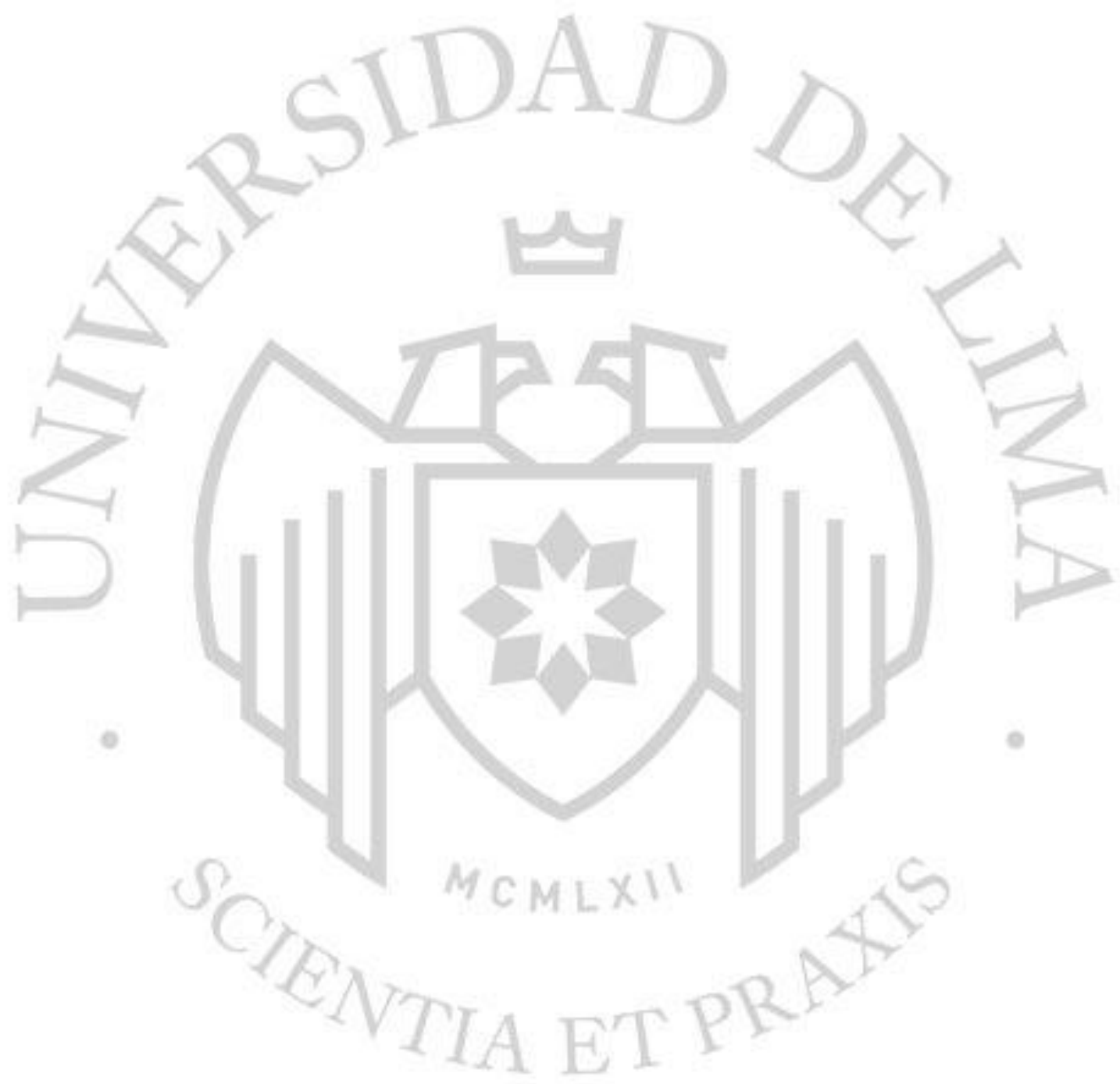




\section{ÍNDICE DE ANEXOS}

ANEXO 1: Cuestionario para docentes "Conociendo el TDAH". .25

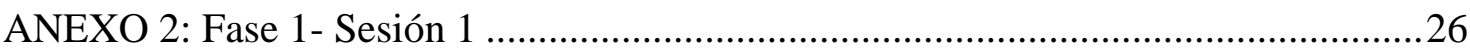

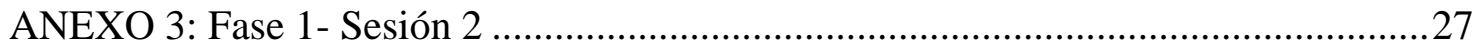

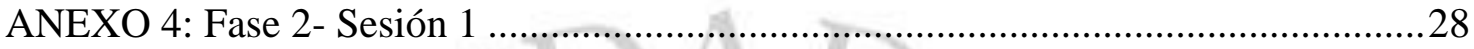

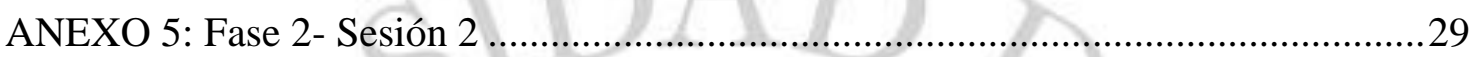

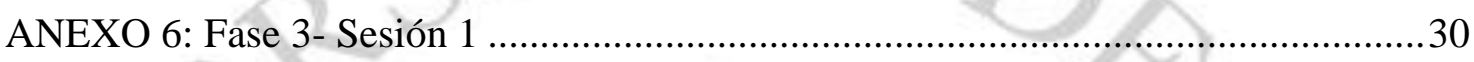

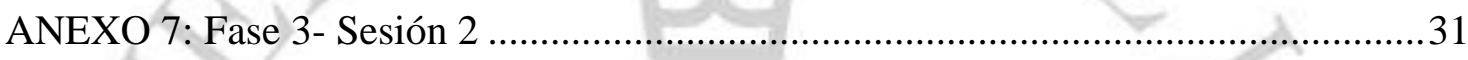

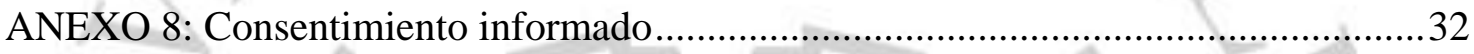

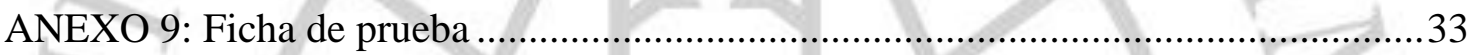

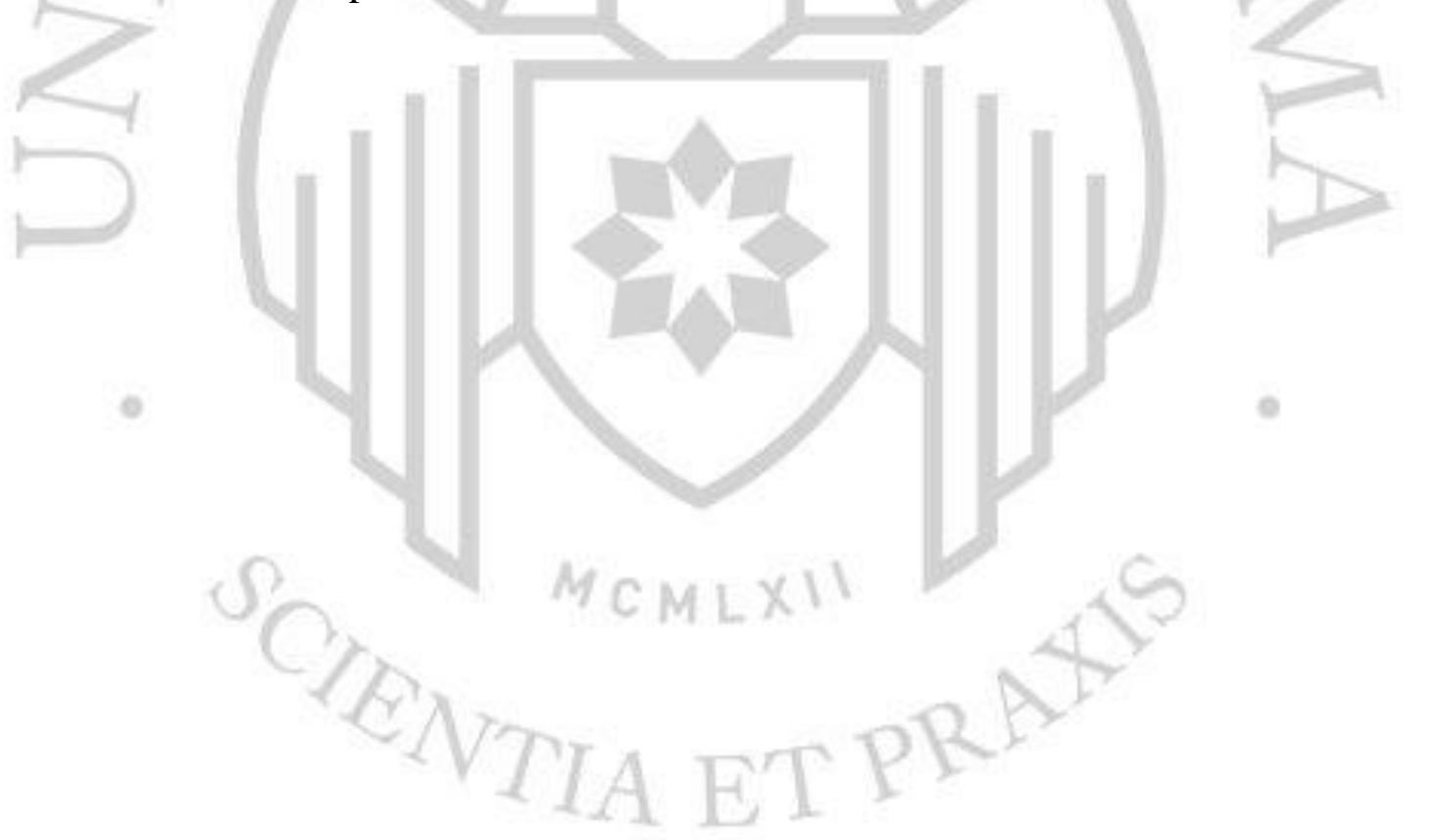




\section{CAPÍTULO I: CONTEXTUALIZACIÓN DE LA PROBLEMÁTICA}

\subsection{Descripción del problema}

Vivimos en una sociedad que cambia constantemente y el contexto de la educación no es ajeno a ello, por lo cual los colegios deben adaptarse también para responder a las demandas y necesidades que se requieren en la actualidad (Domínguez \& Vásquez, 2015; Veloquio,2016). Estos desafíos del sistema educativo están relacionados principalmente a la calidad en la educación y atención a la diversidad (Cornejo, 2017). Es así que, las investigaciones hoy en día, nos sugieren que las escuelas no pueden enfocarse únicamente en el éxito académico, sino que deben prestar mayor interés en la diversidad que caracteriza a cada uno de sus alumnos (Restrepo, Erazo, Ramírez, Vélez \& Alexander, 2016).

Una de las primeras referencias acerca de la necesidad de universalizar el acceso a la educación, la encontramos en la Conferencia Mundial sobre Educación para Todos de 1990, donde se señala que las necesidades básicas de aprendizaje son un derecho de todos los niños. Cuatro años más tarde, tuvo lugar la Conferencia Mundial de Salamanca, donde se buscó reducir las desigualdades con mayor énfasis, pues si bien, el foco principal fueron aún las necesidades educativas especiales, las propuestas señaladas buscaban resaltar el reconocimiento de la diversidad de los alumnos (Duk \& Murillo, 2018).

En sí, la diversidad nos habla de aquellas diferencias individuales que hacen que cada ser sea único. En la escuela, hace referencia a las diferencias en el ritmo para aprender, los estilos de aprendizaje, las capacidades y las motivaciones que los alumnos tienen. Atender la diversidad implica entonces todo aquello que se realice con el fin de evitar que nuestras diferencias se conviertan en desigualdades (Cornejo, 2017).

Balongo \& Mérida (2016) refieren que la atención a la diversidad es de suma importancia en las escuelas porque enriquece las relaciones en grupo y crea ambientes de cooperación. Asimismo, trae beneficios al país, pues como señala Cornejo (2017), cuando los estudiantes se sienten comprometidos con la educación, buscan realizar cambios en beneficio de la sociedad. 
En este proceso de atención a la diversidad, el profesor es un elemento clave que se enfrenta también a nuevos desafíos. Ello implica que actúen pedagógicamente en beneficio de todos y cada uno de los estudiantes, logrando satisfacer sus necesidades básicas de educación (Veloquio, 2016; Paz, 2017; Begonia, 2019). Generalmente, tienden a utilizar métodos tradicionales al enseñar, esperando que todos aprendan lo mismo, de la misma manera y al mismo ritmo, sin embargo, hoy en día, al toparse con estudiantes con distintas formas de aprendizaje, la enseñanza para ellos se vuelve todo un reto (Restrepo et al. ,2016).

La realidad nos señala que, en la actualidad, los docentes no cuentan con herramientas que permitan hacer frente a las necesidades de todos sus estudiantes (Paz, 2017). Esa deficiencia podemos verla desde la formación universitaria, donde no se les ofrece un enfoque real y sensible a las diferencias del alumnado (Domínguez \& Vásquez, 2015), hasta en el concepto que tienen acerca de lo que implica atender la diversidad. Como señalan Muñoz, López y Assael (2015) los docentes tienen diversas perspectivas, pero se enfocan más en un diagnóstico o en lo que el alumno no puede realizar. Suelen por lo común, relacionar la atención a la diversidad con Necesidades Educativas Especiales derivadas de alguna condición de discapacidad (Balongo \& Mérida, 2015; Begonia, 2019).

Para el docente, el desafío es mayor si dentro de la población escolar se encuentran alumnos con TDAH (Trastorno de Déficit de Atención e Hiperactividad). En la actualidad es un trastorno con gran prevalencia que está ligado casi siempre a problemas de conducta y fracaso escolar (Informe del Consejo Escolar de Navarra, 2015).

Los alumnos con TDAH presentan habilidades que otros no tienen y carecen de algunas que generalmente todos poseemos, por ello, existe la necesidad de contar con profesores mejor preparados para responder a este tipo de diversidad (Vásquez \& Villa, 2018). Frecuentemente son ellos quienes detectan los primeros síntomas de este trastorno, y pueden favorecer el aprendizaje si manejan las herramientas pedagógicas adecuadas. Asimismo, el docente puede garantizar el éxito en estos alumnos al intervenir no sólo en el proceso de aprendizaje sino en su integración al centro educativo (González, 2018).

Con respecto a la Institución educativa donde se realiza este proyecto, cabe indicar que se ha dado un aumento de alumnos retirados, siendo una de las causas la falta de atención a los estudiantes de la diversidad y la carencia de herramientas de los docentes para intervenir en ello. Así también, se señala dentro de las soluciones, la necesidad de promover charlas, capacitaciones y reuniones que aborden estos temas. 
En el centro educativo, si bien existen sólo 12 alumnos diagnosticados con TDAH (7 secundaria y 5 en primaria), se encuentran 61 estudiantes (34 en primaria y 27 en secundaria) con características atencionales y comportamentales referentes a una presunción diagnóstica de TDAH. Por otro lado, vale mencionar que en el plantel laboran setenta docentes, pero solamente cuatro de ellos cuentan con algún estudio referente a atención a la diversidad o afines.

En resumen, después de lo expuesto, se considera realmente necesario implementar un plan de capacitación a los docentes en atención a la diversidad enfocado principalmente en alumnos con TDAH o aquellos con déficit atencional y comportamental con presunción diagnóstica de ello.

\subsection{Análisis institucional}

La Institución pertenece al sector público y brinda el servicio de educación básica regular en Lima Metropolitana. Inicia sus labores en 1985 y cuenta en la actualidad con los niveles primaria y secundaria, tanto para el turno mañana como tarde.

Asisten en su totalidad un aproximado de 2000 estudiantes, provenientes en un 50\% del distrito de San Borja, un 45\% de los distritos de, Surquillo, Surco, San Luis, San Juan de Miraflores, Villa María, Villa el Salvador, San Juan de Lurigancho y la Victoria, y un 5\% de extranjeros. La población se caracteriza por ser diversa y pluricultural (PEI PAT 2019).

En el centro educativo trabajan 70 docentes, 29 en primaria y 41 en secundaria, en su mayoría en calidad de nombrados por el Estado, por lo cual la rotación del personal es realmente baja. Cabe mencionar que el tiempo de antigüedad de los maestros en la Institución fluctúa entre los quince y treinta años de labor.

Así también, desde 2016 se encuentra un espacio destinado a brindar soporte emocional, cognitivo y pedagógico llamado TOE (Tutoría y Orientación Educativa), donde se atienden diversas necesidades de los alumnos, docentes y padres de familia. En esta área labora una licenciada y colegiada en psicología, así como seis universitarios en calidad de internos.

Con respecto a la misión, son una Institución líder en su distrito, que brinda una formación integral basada en valores y principios acordes a la vanguardia, con docentes capacitados y una infraestructura adecuada. Así también, tiene por visión brindar un servicio de calidad a los estudiantes, promoviendo sus habilidades y capacidades para formarlos como 
emprendedores, capaces de construir una sociedad con inclusión y responsabilidad ambiental (PEI PAT, 2019)

El centro educativo desarrolla valores como Justicia, empatía, solidaridad, responsabilidad, y respeto. Asimismo, cuentan con compromisos en los que se señala siempre la disposición a enseñar bajo las condiciones y oportunidades que cada alumno necesita.

Sin embargo, si bien el centro aspira a la modernización educativa, tomando en cuenta el respeto por las diferencias, se ha encontrado que la mayoría de docentes utilizan modelos tradicionales de impartir conocimientos que no se ajustan a los nuevos enfoques. Esta falta de capacitación hace que no cuenten con herramientas necesarias para atender la diversidad en el aula. 


\section{CAPÍTULO II: MARCO TEÓRICO Y ANTECEDENTES}

\subsection{Diversidad}

La diversidad es un atributo que nos caracteriza como individuos (Domínguez \& Vásquez, 2015), es la cualidad de ser únicos y diferentes (Gimeno 2000 en Barrero \& Rosero 2018).

Para Ágreda, Alonso \& Rodríguez (2016) la diversidad es una característica inherente a los seres humanos ya que cada persona tiene una forma de interpretar la realidad y estas diferencias pueden ser por la cultura, la capacidad, necesidades, madurez o condiciones personales.

\subsubsection{Atención a la diversidad}

La atención a la diversidad surge para responder a aquellas diferencias individuales del alumnado (Cejudo, Díaz, Losada \& Pérez-Gonzáles 2016) y así brindar soluciones a través de medidas adaptadas a sus características y necesidades al enfrentar las exigencias escolares (Cornejo, 2017). Por lo tanto,

La atención a la diversidad se entiende a nivel general como el conjunto de actuaciones educativas dirigidas a dar respuesta a las diferentes capacidades, ritmos y estilos de aprendizaje, motivaciones e intereses, situaciones sociales, culturales, lingüísticas y de salud del alumnado. Constituye, por tanto, un principio fundamental que debe regir a todos los niveles educativos, asegurando la igualdad de oportunidades de todos los estudiantes ante la educación y evitar, en la medida de lo posible, el fracaso escolar y el consecuente riesgo de abandono del sistema educativo. (Cornejo, 2017, p. 5)

En el Perú, también se toma en cuenta la atención a la diversidad, así pues, el sistema educativo el cual basa sus principios en la Ley General $N^{\circ} 28044$, muestra en su artículo 8 lo siguiente: "La equidad, que garantiza a todos iguales oportunidades de acceso, permanencia y trato en un sistema educativo de calidad” (Ley General de Educación, 2003, p. 2).

Asimismo, Duk, Cisternas \& Ramos (2019) señalan que atender la diversidad es un gran desafío en las escuelas y para ello se forma la educación inclusiva, para avanzar hacia el reconocimiento de estas diferencias y dar así una respuesta educativa de calidad. La inclusión, 
por lo tanto, ha de ser vista como una búsqueda constante de mejores maneras de responder a la diversidad del alumnado (Echeita y Ainscow, 2011 en Ortiz, López, Figueredo y Martin, 2018).

Cabe mencionar que aún se sigue manteniendo un concepto de atención a la diversidad muy sesgado, ya que se le asocia comúnmente con situaciones de déficit o vulnerabilidad (Barrero \& Rosero 2018). Como señala Cornejo (2017), la inclusión educativa no debe limitarse a los estudiantes con algún tipo de discapacidad, sino que debe garantizar el aprendizaje de toda una población estudiantil.

\subsection{Trastorno por déficit de atención e hiperactividad}

\subsubsection{Concepto de TDAH}

Dentro de la diversidad, podemos señalar a la población con Trastorno por Déficit de Atención e Hiperactividad. En su última versión DSM V, el TDAH es considerado un trastorno del neurodesarrollo caracterizado por un patrón persistente de inatención y/o hiperactividad-impulsividad que interfiere en el desarrollo y funcionamiento de quien lo padece. Se señala además tres subtipos: predominantemente inatento, predominantemente impulsivo-hiperactivo o de tipo combinado. (American Psychiatric Association [APA], 2013).

Las estadísticas indican que a nivel mundial presenta una prevalencia entre 5 y $9 \%$ en la población de niños y adolescentes (Faraone, 2003 en Fernández, Piñón, Vásquez-Justo, 2017 ; Reyes, 2015)

Si bien la inatención, hiperactividad e impulsividad en el TDAH es lo más visible, cabe indicar que, afecta otros ámbitos de la vida del niño, como lo familiar, social y sobre todo lo educativo (Molina \& Martínez-Gonzáles 2015).

\subsubsection{TDAH en los centros educativos}

Muchos autores reconocen al TDAH como el trastorno más común de la etapa escolar (Valda, Suñagua \& Coaquira, 2018).

Sobre el TDAH en la escuela (Hannah, 2002 en Arroyo 2018) comenta que:

un $70 \%$ de los que son "inatentos" manifiestan problemas de tipo académico que afectan al aprendizaje de distintas materias, mientras que el 30\% de ellos 
tienen problemas de conducta. Para los que presentan "hiperactividad e impulsividad" los porcentajes se invierten, con un $75 \%$ de problemas conductuales y un $25 \%$ con dificultades académicas. (p3)

En sí, a los estudiantes con este cuadro les cuesta adaptarse al centro educativo, puesto que las actividades escolares le representan un esfuerzo mayor que el común de los alumnos (Sanz, 2017). Se tienen dificultades para el aprendizaje de los contenidos curriculares, pero también para lograr integrarse en el grupo (DuPaul, 2004 en Arroyo 2018)

Puede decirse que los alumnos que presentan TDAH, son los más complicados de tratar en un aula de clases y frecuentemente son señalados como malcriados o deficientes (Gamarra, Mendoza, León, León \& Campos, 2017).

\subsubsection{Modelo de dificultades para la Inhibición de Barkley}

Existe una variedad de modelos explicativos que pretenden dar una visión más completa del TDAH, aunque ninguno se ha consolidado plenamente (Rubio, Castrillo, Herreros, Gastaminza \& Hernández, 2016). Sin embargo, uno de los más influyentes a la fecha es el de Russell Barkley, quien señala que la dificultad de este trastorno radica en la inhibición de la conducta (Orozco \& Zuluaga, 2015; Molina \& Martínez-Gonzáles, 2015).

Este modelo de base neuropsicológica muestra que la dificultad se encuentra en la inhibición de impulsos, los cuales llevan a que las funciones ejecutivas no operen adecuadamente. Estas funciones son necesarias para planificar, organizar, revisar y evaluar el comportamiento para alcanzar metas. (Barkley, 1997 en Arcos 2014)

Para Barkley (1997) las cuatro funciones ejecutivas afectadas son:

a) Memoria de trabajo no verbal: que permite retener la información del pasado en la mente para orientar las acciones de la persona en el presente. Esta memoria se desarrolla entre los 3 meses y los 10 años.

b) Memoria de trabajo verbal: implica aquellas conversaciones que tienen lugar en el interior de cada persona y que son necesarias para regular la conducta.

c) Inhibir reacciones: La capacidad para internalizar las emociones, sentimientos y la motivación para no mostrarla de manera impulsiva. 
d) Capacidad para realizar procesos de síntesis y análisis o reconstitución: Es aquella que permite planificar y solucionar problemas. Los niños con TDAH presentan mayor dificultad para buscar alternativas ante determinadas situaciones.

Asimismo, con respecto a la atención Barkley sostiene que:

El déficit de atención se centra en la atención sostenida (la dependiente del contexto y la autorregulada, dirigida a una meta, controlada y motivada internamente), concepto sustentado no en que el estudiante con TDAH no pueda focalizar la atención o prestar atención a diversos acontecimientos interesantes, sino fundamentada en la dificultad para prestar atención a los estímulos de forma persistente. (Barkley 1997 en Estévez \& León 2015 p3) 


\section{CAPÍTULO III: OBJETIVOS GENERAL Y ESPECÍFICOS}

\subsection{Objetivo general}

"Concientizar y capacitar a los docentes en la importancia de la atención a la diversidad en alumnos con TDAH"

\subsection{Competencia general}

Implementa estrategias metodológicas para la atención a la diversidad de alumnos con TDAH.

\subsection{Resultados de aprendizaje}

- Conoce la definición y conceptos de atención a la diversidad y del TDAH.

- Selecciona estrategias metodológicas para la atención a la diversidad de alumnos con TDAH

- Contrasta la metodología de enseñanza tradicional con el modelo de atención a la diversidad para alumnos con TDAH. 


\section{CAPÍTULO IV: METODOLOGÍA DE LA EVALUACIÓN Y DE LA INTERVENCIÓN}

\subsection{Evaluación de línea base}

La Institución educativa registra 12 alumnos con diagnóstico de TDAH distribuidos en ambos niveles quienes han sido reportados al tutor o al área de TOE por los propios padres de familia.

Asimismo, también se registra un número de 34 alumnos en primaria y 27 en secundaria con signos propios de TDAH. Estos 61 estudiantes presentan diversas características, entre las que resaltan las siguientes: dificultades en atención, seguimiento de órdenes e instrucciones, inconvenientes en tareas y actividades escolares, mantenerse en constante movimiento, presentar conductas disruptivas.

Asimismo, la problemática en estos alumnos va de la mano con, bajo rendimiento académico, inasistencias, abandono de aula en horas de clase, indisciplina, problemas de aprendizaje, posibilidad de repitencia de año escolar, entre otros.

Por otro lado, en la institución educativa laboran 70 docentes, de los cuales únicamente 4 de ellos tienen especialización en temas referentes a la diversidad o inclusión. Para ser más específico, sólo dos de ellos cuentan con cursos de atención a la problemática en TDAH.

\subsubsection{Participantes}

Para la elaboración de la línea de base, se tomó en cuenta el total de docentes que laboran en el centro educativo (70).

Se determinó bajo el criterio de exclusión, considerar a los docentes que cumplen la función de tutores de aula, debido a la responsabilidad en el acompañamiento académico y socioemocional en relación a sus alumnos, es por ello que de los 70 docentes únicamente el programa estará dirigido a 53 según el criterio antes mencionado, los mismos que se encuentran distribuidos 25 en nivel primario y 28 en el nivel secundario.

\subsubsection{Técnicas y/o instrumentos de evaluación/ diagnóstico}

El instrumento utilizado para la elaboración de la línea base ha sido una encuesta de creación propia denominada "Conociendo el TDAH" (Anexo 1). Es de tipo anónimo y consta de 10 ítems de los cuales, 1 es de desarrollo y los otros 9 son de opción múltiple. 
Los ítems están categorizados de la siguiente manera: Conocimiento, Competencia y Actitud.

En la categoría Conocimiento se encuentran los ítems 1, 2,9

En la categoría Competencia se encuentran los ítems 3, 4, 5, 6

En la categoría Actitud se encuentran los ítems 7,8, 10

\subsubsection{Procedimiento de evaluación de línea base}

Los integrantes del departamento de TOE entregaron las encuestas a los 53 tutores del centro educativo, dando como lapso tres días para recogerlas. Se utilizaron las técnicas estadísticas del programa Excel para procesar la información y luego de analizar los datos se observó lo siguiente:

En la categoría Conocimientos, si bien, 58\% de tutores conoce qué es el TDAH, 49\% señaló conocer poco y $45 \%$ casi nada de lo que implica. Así también, al solicitarle mencionar conductas presentes en el TDAH, sólo el $4 \%$ de tutores mencionó correctamente 3 conductas presentes, mientras que $38 \%$ no acertó con ninguna.

Con respecto al tipo de educación más adecuado para un alumno con TDAH, $68 \%$ de tutores considera el sistema de inclusión como la mejor opción, mientras que $26 \%$ opta por un colegio especial y sólo $6 \%$ por educación regular.

En la categoría Competencia, $81 \%$ de los tutores señaló no contar con los conocimientos necesarios para detectar a un estudiante con TDAH en sus aulas, así como 75\% de ellos, indicaron no sentirse capacitados para atender un caso como este.

Igualmente, $89 \%$ señaló no conocer estrategias de intervención que favorezcan el aprendizaje de los alumnos con TDAH, mientras que sólo $6 \%$ de tutores mencionó haber llevado algún tipo de capacitación con respecto a este trastorno.

En la categoría Actitud, se obtuvo que $60 \%$ de tutores considera que atender a un alumno con TDAH no es parte de su rol como docente. Asimismo, $72 \%$ de los participantes no sabe si la incorporación de un alumno con TDAH puede brindar algún tipo de beneficio a los demás estudiantes, mientras que $24 \%$ cree q no es beneficioso y sólo $4 \%$ considera que si es favorable. 
Finalmente, en el caso que el tutor conociera estrategias para atender a un estudiante con estas características, $81 \%$ señala que sí las aplicaría y otro $19 \%$ indica no estar interesado en utilizarlas.

\subsection{Implementación}

El Programa de Capacitación para docentes se desarrollará en 3 fases:

- La fase 1 está orientada a enseñar a los tutores la definición y conceptos de atención a la diversidad y TDAH.

- La fase 2 está orientada a enseñar a los tutores a seleccionar estrategias metodológicas para la atención a la diversidad de alumnos con TDAH.

- La fase 3 está orientada a que los tutores puedan contrastar la metodología de la enseñanza tradicional con el modelo de atención a la diversidad para alumnos con TDAH.

Cada fase está conformada por 2 sesiones de 2 horas y 30 minutos cada una.

La duración del programa es de 6 semanas, llevándose a cabo los días sábados de 9:00 a 11:30 a.m. (Anexo $\mathrm{N}^{\circ} 2$ al N $\mathrm{N}^{\circ}$ )

\subsubsection{Participantes}

En el programa de capacitación participaron 53 tutores del centro educativo, de ambos géneros, entre 30 y 65 años de edad. Todos ellos son licenciados en educación y se encuentran divididos, 25 en el nivel primario y 28 en el nivel secundario.

Como criterio de inclusión se consideró a aquellos que han sido asignados como tutores este año escolar y que hayan firmado y entregado el consentimiento informado.

\subsubsection{Instrumentos o Herramientas de Implementación/ intervención}

Para el programa de capacitación se utilizarán principalmente Exposiciones y Ronda de Preguntas. Así también, los tutores participarán de manera activa a través de técnicas grupales tales como:

Foro: Es un espacio que permite un intercambio de información convirtiendo nuestra experiencia de aprendizaje en algo más efectivo.

Juego de Roles o Role Play, una técnica que permite que los adultos puedan aprender nuevas formas de conducirse e interiorizar los nuevos aprendizajes. 


\subsubsection{Procedimiento de Implementación}

Luego del resultado de la línea base, el departamento de TOE solicitó autorización a la directora del Centro Educativo para realizar el programa de capacitación para docentes en atención a la diversidad de alumnos con TDAH. Se requirió disponer de un aula apropiada para el trabajo, que permita realizar diversas técnicas grupales con los docentes.

La elaboración del programa de capacitación tomó una semana y media, para luego buscar la aprobación de la encargada del área de TOE. Se determinó que se divida en tres Fases compuestas por dos sesiones cada una, las cuales tendrían dos horas y media de duración y se darían con una frecuencia de una vez por semana.

Posterior a la aprobación, se realizó la invitación a los tutores del centro educativo. El Programa se dio a conocer con una semana de anticipación y a través de tres medios:

- En un panel ubicado en la parte exterior del área de TOE.

- Un afiche en el pabellón de primaria y otro en el de secundaria.

- Invitación general en el aula de profesores.

Así también, un día previo al inicio del programa, se solicitó la participación de los tutores a través de correos a cargo de los coordinadores de primaria y secundaria según corresponde al nivel donde ejercen.

El primer día del programa de capacitación se les entregó a los tutores, según su llegada, un consentimiento informado que debía ser firmado y devuelto antes de iniciar la sesión. (Anexo 8)

\subsection{Evaluación de proceso}

Una vez concluido el programa de capacitación se pretende evaluar el aprendizaje obtenido por los 53 tutores con respecto a la atención a la diversidad de alumnos con TDAH, a través de la resolución de la encuesta "Conociendo el TDAH".

Se espera que posterior a las seis horas de capacitación, los tutores se encuentren concientizados sobre la importancia de la atención de la diversidad en alumnos con TDAH y tengan capacidad para reconocer conceptos, seleccionar estrategias y contrastar la metodología actual con la propuesta por el programa. 


\subsubsection{Participantes}

Durante el programa de capacitación se mantuvo la cantidad de participantes que fue de 53 tutores.

\subsubsection{Técnicas y/o instrumentos de evaluación/diagnóstico}

El instrumento utilizado para la evaluación del proceso fue la misma encuesta que se utilizó para la elaboración de la línea base denominada "Conociendo el TDAH", la cual ha sido descrita previamente.

\subsubsection{Procedimiento de evaluación de proceso}

Al finalizar la última sesión del programa de capacitación se les entregó a los tutores la encuesta "Conociendo el TDAH”, brindándoles diez minutos para realizarla.

Se les recordó que era de carácter anónimo y se les solicitó entregarla a las internas del área. Finalmente, en el área de TOE se procesó la información con ayuda del programa estadístico de Excel. 


\section{CAPITULO V: RESULTADOS}

\subsection{Resultados descriptivos cuantitativos}

Finalizado el programa de capacitación se alcanzaron los siguientes resultados:

En la categoría Conocimiento, se obtuvo que el 98\% de tutores conoce qué es el TDAH, así como, el 53\% de participantes siente que sabe mucho después de su asistencia al programa. Al solicitarles que mencionen síntomas del trastorno, el 66\% de tutores respondió adecuadamente con tres aciertos, mientras que $26 \%$ de ellos respondió con dos aciertos. No se encontraron desaciertos.

Con respecto a la educación más beneficiosa para un alumno con TDAH, el 83\% de tutores señaló que los colegios regulares son la mejor alternativa, mientras que un 17\% aún considera que deben encontrarse en un programa de inclusión escolar. Ningún tutor indicó la educación especial como opción.

En la categoría Competencia se obtuvo que el $62 \%$ de tutores se siente en condiciones para detectar un posible caso de TDAH en su centro educativo.

Mientras que, con respecto a la capacidad para atender a los alumnos con TDAH, 60\% de ellos señaló sentirse siente muy capacitado, un $28 \%$ lo siente de manera regular y un $11 \%$ aún se siente poco capacitado. Así también, el $98 \%$ de participantes refirió conocer estrategias para atender a este tipo de estudiantes en sus aulas.

Por otro lado, al consultarles si han llevado algún curso, charla o especialidad en TDAH, el total de asistentes respondió afirmativamente.

Por último, en la categoría Actitud se obtuvo que $89 \%$ de tutores considera que atender a un alumno con TDAH si es parte de su rol como docente. Así como, el 96\% de participantes indicó que sí aplicaría estrategias ante el caso de un estudiante con TDAH en el centro educativo.

Finalmente, el $81 \%$ de tutores considera beneficioso tener un alumno con TDAH en aula, mientras que un $11 \%$ indica no saberlo y un $8 \%$ lo considera aún negativo. 
Tabla 1

Resultados comparativos del pre y post intervención

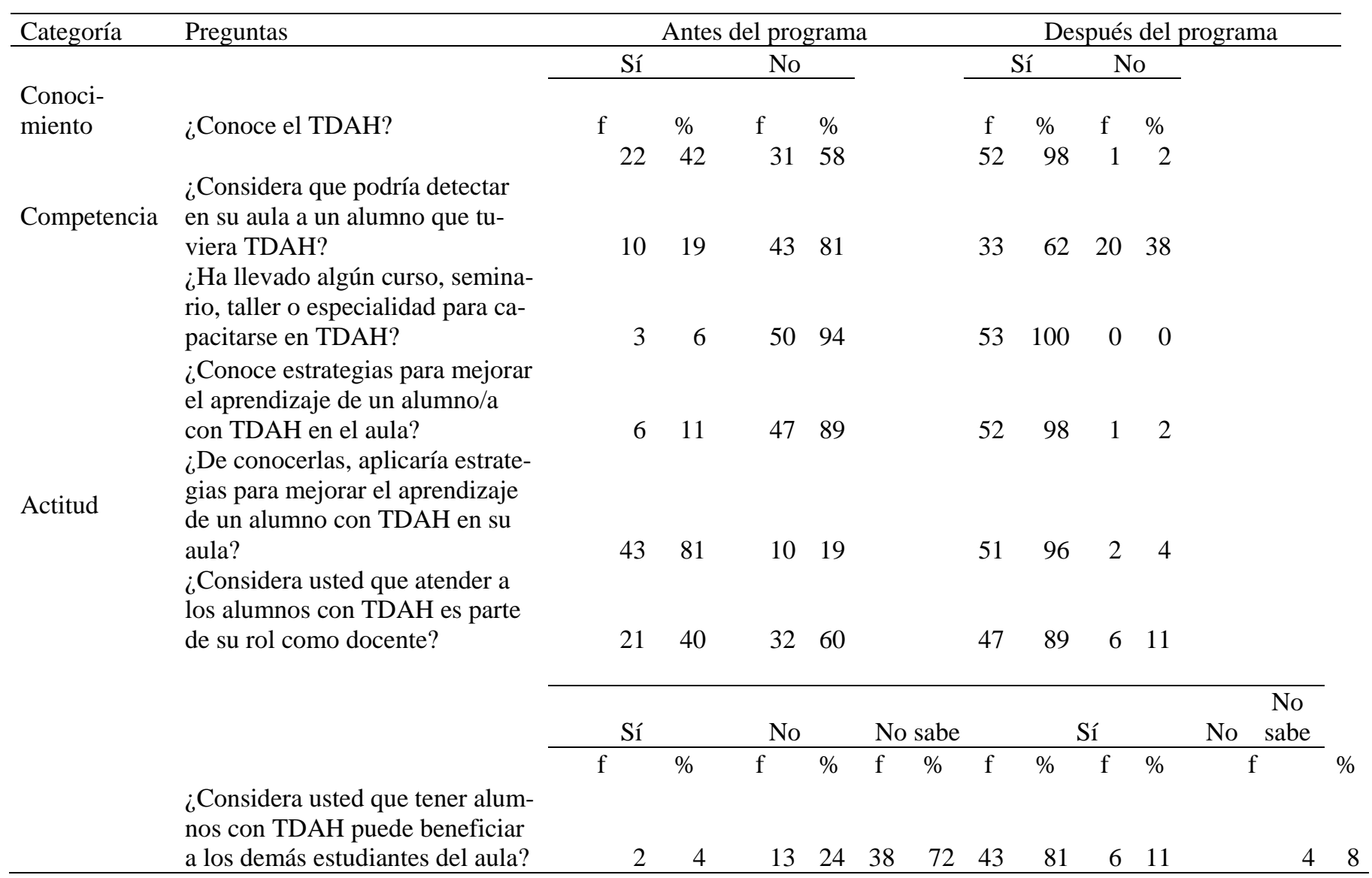

En la Categoría Conocimiento, se observa que en el ítem correspondiente a si conoce el TDAH, antes de la capacitación, $42 \%$ de los docentes indicaron conocerlo, mientras que 58\% señalaron que no lo conocen. Después del programa, 98\% de tutores indicó que sí lo conocía y sólo $2 \%$ que aún no lo conocía.

En la Categoría Competencia, se observa que, en el ítem correspondiente a su capacidad para detectar a un alumno con TDAH en el aula, antes de la prueba 19\% de tutores indicaba que si y $81 \%$ que no podría detectarlo, mientras que después de la capacitación, $62 \%$ indicó poder detectarlo y un $38 \%$ que aún no podría detectarlo.

Con respecto a si ha llevado algún curso para capacitarse en TDAH, antes del programa, el 94\% de tutores indicó que no, mientras que el $6 \%$ mencionó que si ha llevado algún estudio 
referente. Luego del programa, el 100\% de los presentes indicaron haber llevado algún estudio en TDAH.

En relación a si conoce estrategias para mejorar el aprendizaje de un alumno con TDAH, antes del programa $11 \%$ de tutores indicó que si y $89 \%$ que no conocía estrategias. Luego del programa, $98 \%$ de tutores señaló conocer estrategias y sólo el $2 \%$ aún las desconoce.

En la Categoría Actitud, se observa que en el ítem correspondiente a si el docente aplicaría estrategias para mejorar el aprendizaje de un alumno con TDAH si las conociera, antes del programa $81 \%$ indicó que si y $19 \%$ que no las aplicaría. Luego del programa, $96 \%$ señaló que, de conocerlas, sí aplicaría las estrategias y sólo 4\% no las aplicaría.

Con respecto a la pregunta si considera que atender a los alumnos con TDAH es parte del rol docente, antes del programa $40 \%$ indicaba que si y $60 \%$ que no es parte de su labor. Luego del programa, $89 \%$ mencionó que si es parte de su rol, mientras que $11 \%$ señala que atender a estos alumnos con TDAH no es parte de su rol docente.

Finalmente, en relación con el ítem correspondiente a si considera que los alumnos con TDAH pueden beneficiar a los demás estudiantes, antes del programa, $72 \%$ indicó que no sabe, $24 \%$ que no beneficia y sólo $4 \%$ que si es favorable, mientras que después del programa, el $81 \%$ señaló que si es beneficioso, $11 \%$ que no lo es y $8 \%$ aún no lo saben.

\subsection{Resultados interpretativos}

Con respecto al nivel de Conocimiento de los tutores acerca del TDAH, se observó que, en la prueba de entrada sólo un $42 \%$ de ellos conocía este trastorno, mientras que luego del programa, la cifra aumentó a un 98\% de participantes que indicaban conocerlo. Asimismo, con respecto a cuánto es lo que conocían sobre TDAH, se pudo observar que, en la prueba de entrada el puntaje más alto se encontraba en quienes señalaban conocer poco del trastorno, con un 49\%, mientras que, en la prueba de salida, el puntaje más alto se encontró en quienes mencionaban conocerlo mucho, con un 53\%. Además, al solicitar que mencionen tres conductas del TDAH, se veía que antes del programa sólo un $4 \%$ atinaba a responderlas correctamente, mientras que al finalizar la capacitación la cifra aumentó a un 66\% de tutores que pudieron contestar de manera acertada. Todo esto en conjunto, es un indicador de que se ha alcanzado uno de los resultados de aprendizaje propuesto, que consistía en de brindar conocimientos a los tutores acerca del concepto de TDAH y lo que este implica. 
Así también, en relación al mejor tipo de educación para un alumno con TDAH, sólo 6\% de participantes consideraba que los centros educativos regulares eran lo más adecuado para ellos, mientras que al final de la capacitación, la cifra ascendió a 83\%. Este logro muestra que los tutores poco a poco pueden asumir que la diversidad es una característica propia de los centros educativos actuales. (Begonia, 2019).

Con respecto al nivel de Competencia adquirido por los participantes, puede observarse que en la evaluación de entrada sólo el 19\% de ellos señalaba sentirse en condiciones de detectar un posible caso de TDAH en el centro educativo, mientras que al finalizar el programa se observa que esta cifra aumentó a $62 \%$, lo que hace referencia a que los tutores se encuentran más capacitados para aportar en el trabajo multidisciplinario que exige el trastorno. Como ya se mencionó, el docente cumple un rol clave en la atención a la diversidad, más aún en alumnos TDAH ya que este trastorno se detecta generalmente en el centro educativo.

Referente a su capacidad para atender a un alumno con TDAH en el aula, 75\% de los tutores señalaron previamente no sentirse capacitados, sin embargo, en la evaluación de salida ningún participante lo consideró de tal manera. Es así que, en la prueba de salida, un $60 \%$ de ellos se señaló como muy capacitados y un $28 \%$ como medianamente capacitados, lo cual hace inferir que los tutores, después del programa, se sienten más aptos para atender las necesidades que surgen de la diversidad de sus alumnos, principalmente en el TDAH.

Asimismo, se aprecia que antes de la capacitación, sólo el 11\% señalaba conocer estrategias para atender a un alumno con TDAH, mientras que al término del programa esta cifra se elevó considerablemente a un $98 \%$, lo que nos refiere por un lado, a que los tutores pueden beneficiar en el proceso de aprendizaje de sus alumnos ya que cuentan con más herramientas para atender su necesidades y pueden elegir la más útil para cada alumno, y por otro lado, que se ha alcanzado otro resultado de aprendizaje, que consistía en seleccionar estrategias para atender a los alumnos con TDAH.

Por último, en relación a la Actitud de los participantes frente al TDAH, se observa que en la prueba de entrada un $40 \%$ de tutores sentía que atender alumnos con este diagnóstico era parte de su labor como docente, mientras que, en la evaluación de salida, la cifra aumentó a un $89 \%$, Así también, previo al programa de capacitación, un $81 \%$ señaló que, de conocer estrategias, si las aplicaría en alumnos que lo requieran, mientras que en la evaluación de salida un $96 \%$ de tutores señaló lo mismo. Además de ello, en la prueba de entrada, sólo un $4 \%$ de participantes consideraba beneficioso contar con un alumno con TDAH en el aula, mientras que culminado el programa de capacitación el porcentaje de tutores aumento considerablemente a $81 \%$. 
Estos datos nos infieren que los tutores han tenido la capacidad de indagar en sus conocimientos previos y mostrar apertura hacia una nueva forma de atención a los alumnos, lo cual es señal de haber alcanzado el tercer resultado de aprendizaje del programa.

Puede decirse que, por medio de estos aprendizajes se ha alcanzado el objetivo principal propuesto por el programa, que consistía en concientizar a los docentes en atención a la diversidad de alumnos con TDAH.

Por otro lado, cabe señalar que el programa ha generado un impacto positivo en la Institución educativa. En primer lugar, a través de tutores concientizados en atención a la diversidad, la población de alumnos con TDAH, que se encontraba en abandono puede comenzar a recibir oportunidades de integrarse como realmente se requiere, tanto en el aspecto académico como social. Así también, si bien el docente no es el encargado de brindar diagnósticos, cuenta ahora con conocimientos que le permiten detectar principales síntomas del TDAH, por lo cual la población con presunción diagnóstica de TDAH en este colegio, será nuevamente tomada en cuenta para ser descartada o derivada.

En segundo lugar, por medio de la capacitación, los docentes cuentan ya con una gama de estrategias que pueden seleccionar según las necesidades de sus alumnos, lo cual permitirá una real integración de todos los estudiantes, logrando reducir el porcentaje de fracaso y de abandono escolar que venía dándose en la institución.

En tercer lugar, a través de profesionales concientizados en la atención a la diversidad, el centro educativo da un paso más para alcanzar uno de sus objetivos principales que es brindar educación de calidad acorde a la vanguardia.

Por otro lado, cabe señalar que en el programa de capacitación se encontraron algunas limitaciones, entre ellas:

El centro educativo cuenta con un sólo ambiente con proyector, el cual, si bien pudo acoger a los 53 participantes, resultó ser muy pequeño para realizar una serie de dinámicas que tuvieron que ser eliminadas.

El centro educativo no contaba con Internet, una herramienta realmente necesaria tanto para la elaboración de las sesiones, como para la ejecución de las mismas (proyección de videos, mostrar páginas, etc.) 


\section{CONCLUSIONES}

Al finalizar el programa de capacitación, los tutores han logrado conocer la definición y conceptos de atención a la diversidad y del TDAH, lo que les permite tener un panorama más amplio de la realidad de las aulas, este aprendizaje les da capacidad para detectar alumnos que requieren algún tipo de flexibilidad en su enseñanza, representando esto un beneficio a la población diversa, principalmente con TDAH.

Así mismo, por medio del programa de capacitación los tutores cuentan con herramientas que les permiten seleccionar estrategias metodológicas para atender a la diversidad de sus alumnos, principalmente aquellos con TDAH. Además, estas estrategias pueden ser utilizadas para el beneficio de toda la comunidad, no siendo exclusivas de alguna población.

Igualmente, culminado el programa de capacitación los docentes tienen apertura a contrastar la metodología de enseñanza tradicional que han utilizado por años, contra el modelo de atención a la diversidad que viene surgiendo como una nueva necesidad y que se convierte en una exigencia para su labor actual, esto con el objetivo de dar un paso más a la calidad educativa que se pretende en la institución.

Finalmente, se concluye que, si los tutores participantes tienen la capacidad identificar conceptos, seleccionar estrategias y contrastar las metodologías tradicional y actual se encuentran con total facultad para implementar estrategias metodológicas para la atención a la diversidad de alumnos con TDAH. 


\section{RECOMENDACIONES}

Si bien, luego del programa de capacitación, los tutores ya cuentan con conocimientos acerca de la definición e implicancia de la atención a la diversidad, principalmente del TDAH, se sugiere colocar todo este aprendizaje en acción, por ello sería recomendable iniciar un trabajo en conjunto con el área de TOE (Tutoría y Orientación Educativa), buscando promover una serie de actividades orientadas a la detección oportuna de alumnos con TDAH para que puedan ser correctamente atendidos.

Del mismo modo, luego del programa de capacitación, los tutores conocen y pueden hacer uso de diferentes estrategias metodológicas para atender la diversidad de su alumnado, sin embargo, sería recomendable ajustar algunas de estas alternativas a la realidad de un centro educativo público, generalmente caracterizado por un alto número de alumnos por aula, carencias tecnológicas y cuya normativa no es netamente propia sino regida por el Estado.

De igual manera, aunque el programa brindado logró generar en los docentes una apertura que les permite contrastar entre la metodología tradicional y la de atención a la diversidad, se cree que aún esto es un pequeño paso, por lo cual se recomienda seguirles fomentando el interés por la constante capacitación, hasta lograr que el concepto de diversidad sea para ellos inherente a la educación actual.

Asimismo, habiendo logrado el objetivo de concientizar a los tutores en atención a la diversidad de alumnos con TDAH, se sugiere crear una comisión, la cual estaría conformada por un grupo de docentes participativos y responsables de la atención a la diversidad, que promuevan el respeto por todos los integrantes del centro educativo sea cual fuese su necesidad educativa, así como, promotor de la cultura de la atención a la diversidad en el centro educativo. 


\section{REFERENCIAS}

Ágreda, M., Alonso, S. y Rodríguez, A. (2016). El concepto de diversidad entendido por los futuros docentes. Revista Sonda: Investigación y Docencia en las Artes y Letras, (5), 9-17. Recuperado de https://idus.us.es/handle/11441/69011;jsessionid=E47684F1F76FA4AAC965F6AECFFA578F?

American Psychiatric Association (2013). Diagnostic and Statistical Manual of Mental Disorders, 5th. Edition (DSM-5). Washington, DC.: American Psychiatric Association; 2013

Arcos, A. (2014). Análisis de las funciones ejecutivas de niños y niñas con trastorno por déficit atencional/hiperactividad (TDAH) y un grupo control que asisten a programas de atención en la ciudad de Manizales. Trabajo de Grado. Universidad de Manizales, Manizales, Colombia. Recuperado de http://ridum.umanizales.edu.co:8080/xmlui/bitstream/handle/6789/1998/INF\%20FINAL\%20Aura\%20Nury\%20Arcos\%200CT30-2014.pdf?sequence=1\&isAllowed=y

Arroyo, K. (2018) El TDAH: Teoría y Metodología desde la cartografía conceptual. Revista Electrónica Desafíos Educativos REDECI, 3(1), 46-60. Recuperado de http://ciinsev.com/web/revistas/2017-2018/primeraEdicion/REVISTA3/04.pdf

Balongo, E., y Mérida, R. (2016). El clima de aula en los proyectos de trabajo. Perfiles Educativos, 38(152), 146-162. Recuperado de http://www.scielo.org.mx/scielo.php?pid=S018526982016000200146\&script=sci_arttext\&tlng=en

Barkley, R. A. (1997). Behavioral inhibition, sustained attention, and executive functions: constructing a unifying theory of ADHD. Psychological bulletin, 121(1), 65-80. Recuperado de https://psycnet.apa.org/fulltext/1997-02112-004.html

Barrero, A. y Rosero, A. (2018). Estado del Arte sobre Concepciones de la Diversidad en el Contexto Escolar Infantil. Revista Latinoamericana de Educación Inclusiva, 12(1), 39-55 Recuperado de http://dx.doi.org/10.4067/S0718-73782018000100039

Begonia, G. (2019) Educar en y para la Diversidad de Alumnos en Aulas de Escuelas Primarias de la Ciudad de México. Revista Latinoamericana de Educación Inclusiva, 13(2), 209225. Recuperado de https://scielo.conicyt.cl/scielo.php?pid=S0718$73782019000200209 \&$ script=sci_arttext\&tlng=en

Cejudo, J., Díaz, M., Losada, L. y Pérez-Gonzáles, J. (2016). Necesidades de formación del maestro de infantil y primaria en atención a la diversidad. Bordón, 68(3), 23-39 doi: https://doi.org/10.13042/Bordon.2016.68402

Cornejo, C. (2017) Respuesta educativa en la atención a la diversidad desde la perspectiva de profesionales de apoyo. Revista Colombiana de Educación, (73), 75-94. Recuperado de https://www.redalyc.org/pdf/4136/413651843005.pdf 
Domínguez, J. y Vázquez, E. (2015). Atención a la diversidad: Análisis de la formación permanente del profesorado en Galicia. Revista Nacional e Internacional de Educación Inclusiva, 8(2), 139-152. Recuperado de https://dialnet.unirioja.es/descarga/articulo/5155168.pdf

Duk, C., Cisternas, T. y Ramos, L. (2019) Formación Docente desde un Enfoque Inclusivo. A 25 Años de la Declaración de Salamanca, Nuevos y Viejos Desafíos. Revista Latinoamericana de Educación Inclusiva, 2019, 13(2), 91-109. Recuperado de http://dx.doi.org/10.4067/S0718-73782019000200091

Duk, C. y Murillo, F. (2018). El Mensaje de la Educación Inclusiva es Simple, pero su Puesta en Práctica es Compleja. Revista latinoamericana de educación inclusiva, 12(1), 11-13. Recuperado de https://scielo.conicyt.cl/scielo.php?pid=S071873782018000100011\&script=sci_arttext\&tlng=e

Estévez, B. y León, M. (2015). Inclusión educativa del alumnado con TDA/H: estrategias didácticas generales y organizativas de aula. Revista de Educación Inclusiva, 8(3). Recuperado de https://revistaeducacioninclusiva.es/index.php/REI/article/view/92

Fernandes, S., Piñón, A. y Vázquez-Justo, E. (2017). Concepto, evolución y etiología del TDAH. Lex Localis, 1(3), 34-60. Recuperado de http://repositorio.uportu.pt:8080/handle/11328/2091

Gamarra O, Mendoza J, León F, León C. y Campos P. (2017) Conocimientos en el trastorno de déficit de atención e hiperactividad en docentes de Chiclayo, Perú. Revista Mexicana de Pediatría, 84(4):134-142. Recuperado de https://www.medigraphic.com/cgi-bin/new/resumenI.cgi?IDARTICULO $=75408$

González, C. (2018) TDAH: nuevas estrategias de diagnóstico e intervención. Punto Rojo Libros.

Informe del Consejo Escolar de Navarra (2015). El TDAH. Navarra. Recuperado de https://consejoescolar.educacion.navarra.es/web1/wp-content/uploads/2015/05/libro-TDAH7.pdf

Ley General de Educación, (2003). Ley N. o 28044. La educación peruana. Título I, Fundamentos y Disposiciones Generales, Artículo $8^{\circ}$. Principios de la educación.

Molina, J. y Martínez-González, A. (2015). Eficacia de una intervención computarizada para mejorar la atención en un niño con TDAH. Revista de Psicología Clínica con Niños y Adolescentes, 2(2), 157-162. Recuperado de http://www.revistapcna.com/sites/default/files/09-6_molina_tdah.pdf

Muñoz, M., López M. y Assaél, J. (2015). Concepciones docentes para responder a la diversidad: ¿Barreras o recursos para la inclusión educativa? Psicoperspectivas, 14(3), 68-79. http://dx.doi.org/10.5027/psicoperspectivas-Vol14-Issue3-fulltext-646

Orozco, N. y Zuluaga, J. (2015). Teoría de la mente en niños y niñas con trastorno por Déficit de Atención con Hiperactividad “TDAH”. Tesis psicológica, 10(2), 134-148. Recuperado de https://www.redalyc.org/pdf/1390/139046451009.pdf 
Ortiz, L., López, E., Figueredo, V. y Martín, A. (2018) Diversidad e inclusión educativa. Barcelona, Ediciones OCTAEDRO.

Paz, C. (2017). Formación inicial de docentes para la atención a la diversidad en contextos inclusivos. Paradigma: Revista De Investigación Educativa, 24(37), 32-47. https://doi.org/10.5377/paradigma.v24i37.6512

PEI PAT (2019) Institución Educativa Pública de Lima Metropolitana. UGEL. Recuperado de http://www.ugel07.gob.pe/wp-content/uploads/2019/09/201909241655.pdf

Restrepo, P., Erazo, M., Ramírez, F., Vélez, R. y Yanza, A. (2016). La diversidad de capacidades para aprender, un valor a ser reconocido en las aulas. Revista Nacional para la Educación Inclusiva, 3(5), $23 \quad-\quad 87 . \quad$ Recuperado de http://ridum.umanizales.edu.co:8080/xmlui/bitstream/handle/6789/2545/Velez_Correa_Ruth_Mary 2015.pdf?sequence $=2 \&$ isAllowed $=y$

Reyes, J. (2015) Programa de apoyo a niños y adolescentes con TDAH. (Máster en Psicopedagogía, Universidad de Valladolid). Recuperado de https://uvadoc.uva.es/handle/10324/14983

Rubio, B., Castrillo, J., Herreros, O., Gastaminza, X., \& Hernández, S. (2016). Perfil y endofenotipos neuropsicológicos en TDAH: Una revisión. Revista de Psiquiatría Infanto-Juvenil, 33(1), 7-20. Recuperado de http://aepnya.eu/index.php/revistaaepnya/article/view/78

Sanz, R. (2017) El TDAH en educación secundaria (Tesis de Licenciatura, Universidad de Valladolid). Recuperado de https://uvadoc.uva.es/bitstream/handle/10324/28375/TFMG815.pdf?sequence=1

Valda, V., Suñagua, R. \& Coaquira, R. (2018). Estrategias de intervención para niños y niñas con TDAH en edad escolar. Revista de Investigación Psicológica, (20), 119-134 Recuperado de http://www.scielo.org.bo/pdf/rip/n20/n20_a10.pdf

Vásquez, M. y Villa, M. (2018) Perspectivas internacionales sobre inclusión, discapacidad y diversidad: Tópicos de la Educación Especial II. México: Editorial Artificios.

Veloquio, G. (2016) La formación permanente de los docentes, ante el desafío de atender a la diversidad educativa. Revista de educación inclusiva, 9(2), 144-154. Recuperado de https://dialnet.unirioja.es/descarga/articulo/4617037.pdf 
ANEXOS 


\section{Anexo 1: Cuestionario para docentes "Conociendo el TDAH"}

Responda con la mayor sinceridad posible. Recuerde que la encuesta es anónima.

1. ¿Conoce Ud. el Trastorno de Déficit de Atención e Hiperactividad (TDAH)?

SI

NO

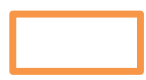

Según su percepción, ¿Cuánto conoce Ud. acerca del TDAH?

Casi nada

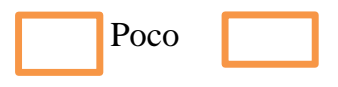

Regular

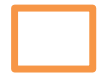

Mucho

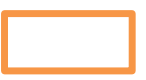

2. Describe 3 conductas que se presentan en el TDAH.

3. ¿Considera Ud. que podría detectar en su aula a un alumno que tuviera TDAH?

SI

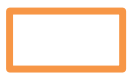

NO

4. ¿Ha llevado algún curso, seminario, taller, especialidad(otros) para capacitarse en TDAH?

SI

NO

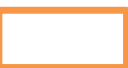

5. ¿Qué tan capacitado se siente Ud. para atender a un alumno con TDAH?

Casi nada
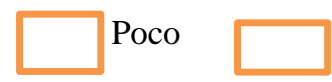

Regular

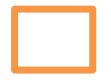

Mucho

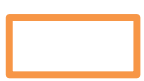

6. ¿Conoce estrategias para mejorar el aprendizaje de un alumno con TDAH en el aula?

SI

$\mathrm{NO}$

7. De conocerlas, ¿aplicaría estrategias para mejorar el aprendizaje de un alumno con TDAH en su aula? SI NO

8. ¿Considera Ud. que atender a los alumnos con TDAH es parte de su rol como docente?? SI

NO

9. ¿Sabe Ud. qué tipo de educación es la más adecuada para un alumno con TDAH?
Regular

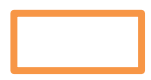
Especial
gular bajo Inclusión

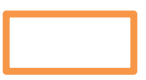

10. ¿Considera Ud. que tener alumnos con TDAH puede beneficiar a los demás estudiantes del aula?

SI

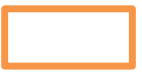

$\mathrm{NO}$

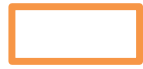

NO LO SABE 


\section{Anexo 2: Fase 1- Sesión 1}

\section{FASE I}

COMPETENCIA GENERAL Implementa estrategias metodológicas para la atención a la diversidad de alumnos con TDAH.

RESULTADO DE APRENDIZAJE Conocer la definición y conceptos de atención a la diversidad y TDAH

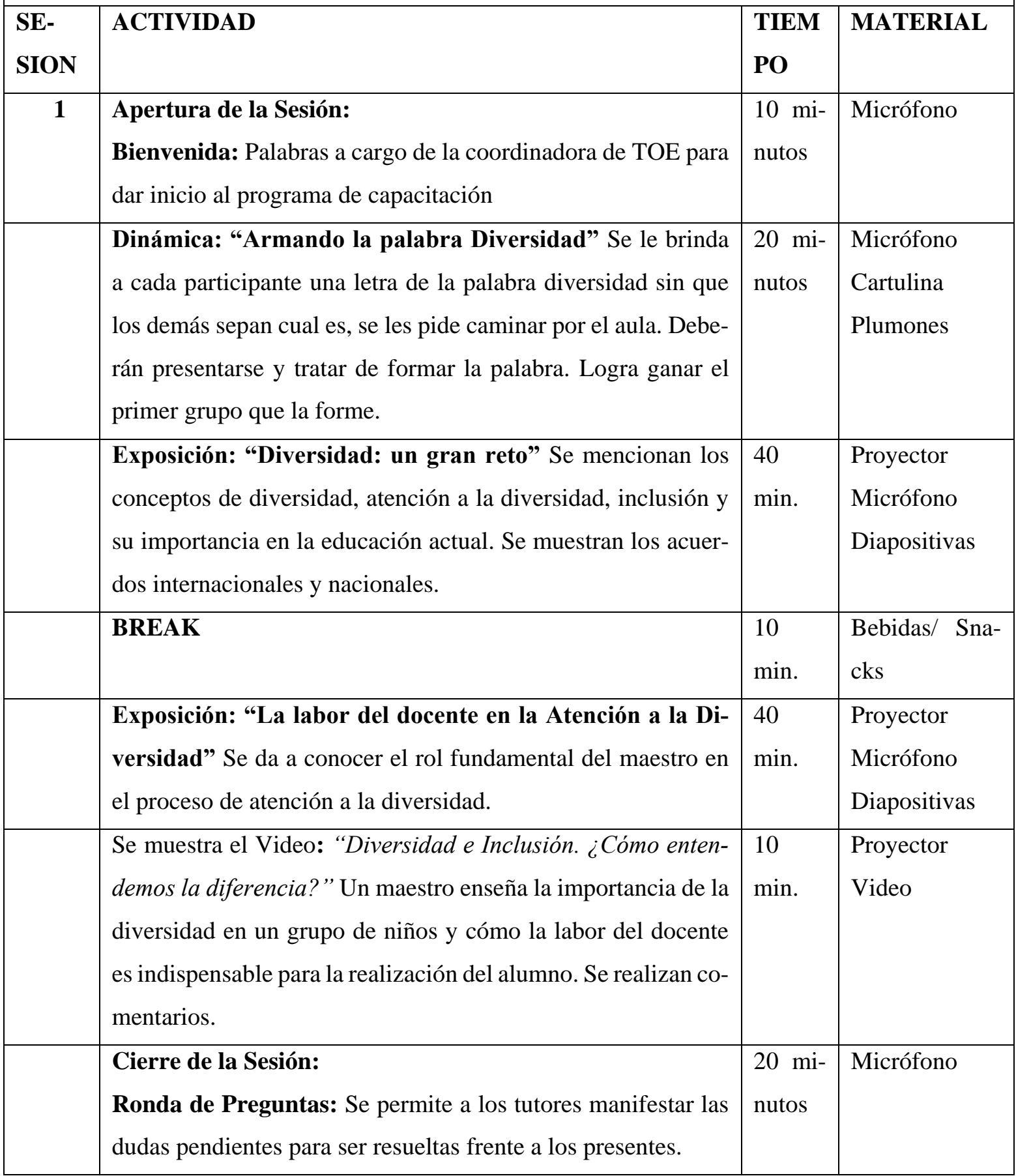




\section{Anexo 3: Fase 1- Sesión 2}

\begin{tabular}{|c|c|c|c|}
\hline \multicolumn{4}{|c|}{ FASE I } \\
\hline \multicolumn{4}{|c|}{$\begin{array}{l}\text { COMPETENCIA GENERAL Implementa estrategias metodológicas para la atención a la diver- } \\
\text { sidad de alumnos con TDAH. }\end{array}$} \\
\hline \multicolumn{4}{|c|}{$\begin{array}{l}\text { RESULTADO DE APRENDIZAJE Conocer la definición y conceptos de atención a la diversidad } \\
\text { y TDAH }\end{array}$} \\
\hline SESION & ACTIVIDAD & TIEMPO & MATERIAL \\
\hline \multirow[t]{5}{*}{2} & $\begin{array}{l}\text { Exposición: "Conociendo el TDAH” } \\
\text { Se brinda información acerca de qué es el TDAH, sus } \\
\text { características, tratamiento actual y principales comor- } \\
\text { bilidades. }\end{array}$ & 40 minutos & $\begin{array}{l}\text { Proyector } \\
\text { Micrófono }\end{array}$ \\
\hline & $\begin{array}{l}\text { Exposición: “TDAH y Funciones Ejecutivas": Se } \\
\text { muestran las } 4 \text { funciones ejecutivas comprometidas en } \\
\text { el TDAH, según la teoría de Barkley y cómo impactan } \\
\text { en la conducta y rendimiento escolar del alumno. }\end{array}$ & 40 minutos & $\begin{array}{l}\text { Proyector } \\
\text { Micrófono } \\
\text { Diapositivas }\end{array}$ \\
\hline & BREAK & 10 minutos & $\begin{array}{l}\text { Galletas } \\
\text { Bebidas }\end{array}$ \\
\hline & $\begin{array}{l}\text { Exposición: "TDAH en mi aula" Se brindan herra- } \\
\text { mientas para detectar posibles casos de alumnos con } \\
\text { TDAH en el aula y la manera cómo se debe proceder. }\end{array}$ & 40 minutos & $\begin{array}{l}\text { Proyector } \\
\text { Diapositivas } \\
\text { Micrófono }\end{array}$ \\
\hline & $\begin{array}{l}\text { Cierre de la Sesión: } \\
\text { Ronda de Preguntas: Se permite a los tutores manifes- } \\
\text { tar las dudas pendientes para ser resueltas frente a los } \\
\text { presentes. }\end{array}$ & $\begin{array}{l}20 \\
\text { minutos }\end{array}$ & Micrófono \\
\hline
\end{tabular}




\section{Anexo 4: Fase 2- Sesión 1}

\begin{tabular}{|c|c|c|c|}
\hline \multicolumn{4}{|c|}{$\begin{array}{ll}\text { FASE II }\end{array}$} \\
\hline \multicolumn{4}{|c|}{$\begin{array}{l}\text { COMPETENCIA GENERAL Implementa estrategias metodológicas para la atención a la diver- } \\
\text { sidad de alumnos con TDAH }\end{array}$} \\
\hline \multicolumn{4}{|c|}{$\begin{array}{l}\text { RESULTADO DE APRENDIZAJE } \\
\text { Seleccionar estrategias metodológicas para la atención a la diversidad de alumnos con TDAH }\end{array}$} \\
\hline SESION & ACTIVIDAD & TIEMPO & MATERIAL \\
\hline \multirow[t]{7}{*}{1} & $\begin{array}{l}\text { Inicio de Sesión: } \\
\text { Video: “Video Pablito un niño que tiene TDAH” Se } \\
\text { muestra la realidad de un niño con TDAH. }\end{array}$ & 10 minutos & Proyector \\
\hline & $\begin{array}{l}\text { Exposición: "Estrategias en el aula 1: Atención Se } \\
\text { dan a conocer estrategias basadas en la propuesta de } \\
\text { APDA, para hacer frente a los problemas atencionales } \\
\text { del alumnado con TDAH }\end{array}$ & 30 minutos & $\begin{array}{l}\text { Diapositivas } \\
\text { Proyector } \\
\text { Micrófono }\end{array}$ \\
\hline & $\begin{array}{l}\text { Exposición: "Estrategias en el aula 2: Hiperactivi- } \\
\text { dad Se dan a conocer estrategias basadas en la pro- } \\
\text { puesta de APDA, para hacer frente a los problemas de } \\
\text { hiperactividad del alumnado con TDAH }\end{array}$ & 30 minutos & $\begin{array}{l}\text { Diapositivas } \\
\text { Proyector } \\
\text { Micrófono }\end{array}$ \\
\hline & Break & 10 minutos & $\begin{array}{l}\text { Bebidas galle- } \\
\text { tas }\end{array}$ \\
\hline & $\begin{array}{l}\text { Exposición: "Estrategias en el aula 3: Impulsividad } \\
\text { Se dan a conocer estrategias basadas en la propuesta de } \\
\text { APDA, para hacer frente a los problemas de impulsivi- } \\
\text { dad del alumnado con TDAH }\end{array}$ & 30 minutos & $\begin{array}{l}\text { Diapositivas } \\
\text { Proyector } \\
\text { Micrófono }\end{array}$ \\
\hline & $\begin{array}{l}\text { Exposición: "Estrategias en el aula 4: Organización } \\
\text { Se dan a conocer estrategias basadas en la propuesta de } \\
\text { APDA, para trabajar la organización en alumnos con } \\
\text { TDAH. }\end{array}$ & 30 minutos & $\begin{array}{l}\text { Diapositivas } \\
\text { Proyector } \\
\text { Micrófono }\end{array}$ \\
\hline & $\begin{array}{l}\text { Cierre de Sesión: } \\
\text { Ronda de preguntas: Se permite a los tutores manifes- } \\
\text { tar las dudas que tengan, para ser respondidas frente a } \\
\text { todo el público. }\end{array}$ & 10 minutos & Micrófono \\
\hline
\end{tabular}




\section{Anexo 5: Fase 2- Sesión 2}

\begin{tabular}{|c|c|c|c|}
\hline \multicolumn{4}{|c|}{ FASE II } \\
\hline \multicolumn{4}{|c|}{$\begin{array}{l}\text { COMPETENCIA GENERAL Implementa estrategias metodológicas para la atención a la diver- } \\
\text { sidad de alumnos con TDAH }\end{array}$} \\
\hline \multicolumn{4}{|c|}{$\begin{array}{l}\text { RESULTADO DE APRENDIZAJE } \\
\text { Seleccionar estrategias metodológicas para la atención a la diversidad de alumnos con TDAH }\end{array}$} \\
\hline SESION & ACTIVIDAD & TIEMPO & MATERIAL \\
\hline \multirow[t]{7}{*}{2} & $\begin{array}{l}\text { Inicio de Sesión: } \\
\text { Dinámica: ¿Quién soy? El moderador coloca nombre } \\
\text { de personas famosas en la espalda de los participantes. } \\
\text { Ellos deberán caminar por el aula haciendo preguntas } \\
\text { de respuesta sólo si o no. }\end{array}$ & 15 minutos & $\begin{array}{l}\text { Plumones } \\
\text { Tarjetas }\end{array}$ \\
\hline & $\begin{array}{l}\text { Exposición: "Estrategias en el aula 5: Sociabiliza- } \\
\text { ción Estrategias basadas en la propuesta de APDA, para } \\
\text { que el alumnado con TDAH pueda fomentar vínculos } \\
\text { adecuados. }\end{array}$ & 30 minutos & $\begin{array}{l}\text { Diapositivas } \\
\text { Proyector } \\
\text { Micrófono }\end{array}$ \\
\hline & $\begin{array}{l}\text { Exposición: "Estrategias en el aula 6: Conducta Se } \\
\text { dan a conocer estrategias basadas en la propuesta de } \\
\text { APDA, para hacer frente a los problemas conductuales } \\
\text { del alumnado con TDAH }\end{array}$ & 30 minutos & $\begin{array}{l}\text { Diapositivas } \\
\text { Proyector } \\
\text { Micrófono }\end{array}$ \\
\hline & Break & 10 minutos & $\begin{array}{l}\text { Bebidas galle- } \\
\text { tas }\end{array}$ \\
\hline & $\begin{array}{l}\text { Dinámica: Los animales: Para dividirse en grupos más } \\
\text { pequeños. Se reparten papelitos a los tutores con distin- } \\
\text { tos animales y deberán buscarse haciendo el sonido del } \\
\text { animal. }\end{array}$ & 15 minutos & $\begin{array}{l}\text { Tarjetas de pa- } \\
\text { pel } \\
\text { Plumones }\end{array}$ \\
\hline & $\begin{array}{l}\text { Análisis de Casos: Se dividen en grupos de } 7 \text { u } 8 \text { par- } \\
\text { ticipantes y se entrega un caso a cada grupo, deben apli- } \\
\text { car las estrategias aprendidas y al final comentarlas } \\
\text { frente a todos los participantes. }\end{array}$ & 45 minutos & $\begin{array}{l}\text { Diapositivas } \\
\text { Proyector } \\
\text { Micrófono }\end{array}$ \\
\hline & $\begin{array}{l}\text { Cierre de Sesión: } \\
\text { Técnica Balance del día: Solicitar que los tutores ver- } \\
\text { balicen lo más resaltante de este día de aprendizaje }\end{array}$ & 5 minutos & Micrófono \\
\hline
\end{tabular}




\section{Anexo 6: Fase 3- Sesión 1}

\begin{tabular}{|c|c|c|c|}
\hline \multicolumn{4}{|c|}{$\begin{array}{ll}\text { FASE III } \\
\end{array}$} \\
\hline \multicolumn{4}{|c|}{$\begin{array}{l}\text { COMPETENCIA GENERAL Implementa estrategias metodológicas para la atención a la diver- } \\
\text { sidad de alumnos con TDAH }\end{array}$} \\
\hline \multicolumn{4}{|c|}{$\begin{array}{l}\text { RESULTADO DE APRENDIZAJE } \\
\text { Contrastar la metodología de enseñanza tradicional con el modelo de atención a la diversidad para } \\
\text { alumnos con TDAH }\end{array}$} \\
\hline $\begin{array}{l}\text { SE- } \\
\text { SION }\end{array}$ & ACTIVIDAD & TIEMPO & MATERIAL \\
\hline \multirow[t]{5}{*}{1} & $\begin{array}{l}\text { Inicio de la Sesión: } \\
\text { Dinámica: El Mensajero: Se debe construir algo con } \\
\text { bloques y luego taparlo para que nadie lo vea. Dividimos } \\
\text { en grupos de } 10 \text { y les damos un paquete de bloques a } \\
\text { cada grupo. Se elige a un mensajero quien podrá ver lo } \\
\text { construido y dará instrucciones de cómo hacerlo similar, } \\
\text { pero sin poder tocar ningún bloque. }\end{array}$ & 20 minutos & Bloques \\
\hline & $\begin{array}{l}\text { Exposición: "La escuela tradicional" Se muestran las } \\
\text { características de la metodología tradicional, técnicas } \\
\text { utilizadas y estilos que aún se mantienen en la actuali- } \\
\text { dad. }\end{array}$ & 45 minutos & $\begin{array}{l}\text { Proyector } \\
\text { Micrófono }\end{array}$ \\
\hline & Break & 10 minutos & $\begin{array}{l}\text { Bebidas } \\
\text { Galletas }\end{array}$ \\
\hline & $\begin{array}{l}\text { Foro: "Escuela tradicional vs. Atención a la diversi- } \\
\text { dad" Se llevará a cabo una discusión entre los tutores } \\
\text { que permitirá conocer diversos puntos de vista. }\end{array}$ & 60 minutos & Micrófonos \\
\hline & $\begin{array}{l}\text { Cierre de la Sesión: } \\
\text { Video: “Escuela Tradicional”. Se muestra un centro } \\
\text { educativo con metodología tradicional y los perfiles del } \\
\text { docente y alumno bajo ese estilo educativo. }\end{array}$ & 15 minutos & Proyector \\
\hline
\end{tabular}




\section{Anexo 7: Fase 3 - Sesión 2}

FASE III

COMPETENCIA GENERAL Implementa estrategias metodológicas para la atención a la diversidad de alumnos con TDAH

\section{RESULTADO DE APRENDIZAJE}

Contrastar la metodología de enseñanza tradicional con el modelo de atención a la diversidad para alumnos con TDAH.

\begin{tabular}{|c|c|c|c|}
\hline $\begin{array}{l}\text { SE- } \\
\text { SION }\end{array}$ & ACTIVIDAD & TIEMPO & MATERIAL \\
\hline \multirow[t]{8}{*}{2} & $\begin{array}{l}\text { ROL PLAYING: Se dividen en grupos de } 10 \text { u } 11 \text { par- } \\
\text { ticipantes, donde se busca representar al docente tradi- } \\
\text { cional, al docente bajo el nuevo enfoque, al alumno con } \\
\text { TDAH y estudiantes del aula, recreando el contraste } \\
\text { bajo ambas metodologías. }\end{array}$ & 60 minutos & $\begin{array}{l}\text { Sillas } \\
\text { Carpetas } \\
\text { Pizarra }\end{array}$ \\
\hline & $\begin{array}{l}\text { Reflexión: Se brindan comentarios acerca de la expe- } \\
\text { riencia vivida a través del juego de roles }\end{array}$ & 10 minutos & Micrófono \\
\hline & Break & 10 minutos & $\begin{array}{l}\text { Bebidas } \\
\text { Galletas }\end{array}$ \\
\hline & $\begin{array}{l}\text { Exposición: "Escuelas que atienden la diversidad" Se } \\
\text { muestran características propias de una escuela con } \\
\text { apertura a la diversidad y se brindan recomendaciones } \\
\text { para alcanzarla. }\end{array}$ & 30 minutos & $\begin{array}{l}\text { Proyector } \\
\text { Diapositivas }\end{array}$ \\
\hline & $\begin{array}{l}\text { Video: "Las vidas de Mario" se compara a Mario con } \\
\text { TDAH bajo un entorno favorecedor y el mismo niño si } \\
\text { no hubiese recibido ayuda de su entorno. Se brindan co- } \\
\text { mentarios acerca del video. }\end{array}$ & 10 minutos & $\begin{array}{l}\text { Vídeo } \\
\text { Proyector }\end{array}$ \\
\hline & $\begin{array}{l}\text { Encuesta: Se entrega a cada participante la encuesta } \\
\text { "Conociendo el TDAH" para corroborar el aprendizaje } \\
\text { alcanzado. }\end{array}$ & 10 minutos & Encuestas \\
\hline & $\begin{array}{l}\text { Entrega de Certificados: Se reparte un diploma por } \\
\text { parte de la Institución educativa señalando el nombre del } \\
\text { programa y la cantidad de horas asistidas. }\end{array}$ & 10 minutos & $\begin{array}{l}\text { Certificados } \\
\text { firmados por } \\
\text { la Institución }\end{array}$ \\
\hline & $\begin{array}{l}\text { Clausura del Programa: } \\
\text { Palabras de despedida de la coordinadora de TOE agra- } \\
\text { deciendo la participación de los tutores. }\end{array}$ & 10 minutos & Micrófono \\
\hline
\end{tabular}




\section{Anexo 8: Consentimiento informado}

\section{CONSENTIMIENTO INFORMADO \\ PARTICIPANTE ADULTO}

Yo, , identificado con DNI acepto de manera voluntaria participar en el Programa de capacitación en atención a la diversidad a alumnos con TDAH que será realizado por el área de Tutoría y Orientación Educativa (TOE) del Centro Educativo XXXX.

El programa tiene como finalidad, concientizar a los docentes en atención a la diversidad a alumnos con TDAH.

Lima, de del 20XX

Firma del participante 


\section{Anexo 9: Ficha de prueba}

FICHA TÉCNICA DE INSTRUMENTO DE EVALUCIÓN

\begin{tabular}{|l|l|}
\hline Nombre del Test: & Encuesta "Conociendo el TDAH" \\
\hline Autor: & Heidi Noriega Solari \\
\hline Modo de aplicación: & Individual. \\
\hline Ámbito de aplicación: & Docentes de primaria y secundaria \\
\hline Edades: & Entre $21-60$ años \\
\hline Duración: & 10 minutos \\
\hline Finalidad: & $\begin{array}{l}\text { Brinda una referencia acerca del conocimiento, la capacidad } \\
\text { para atenderlo y la actitud que se tiene frente al TDAH }\end{array}$ \\
\hline Composición/estructura: & $\begin{array}{l}\text { La encuesta "Conociendo el TDAH" está conformada por 10 } \\
\text { ítems: 9 para marcar y 1 para redactar. } \\
\text { Se enfoca en tres áreas: } \\
\text { Conocimiento: hace referencia a cuanto conoce sobre TDAH }\end{array}$ \\
& $\begin{array}{l}\text { Competencia: hace referencia a si sabe intervenir en un caso de } \\
\text { TDAH } \\
\text { Actitud: hace referencia a si hay interés de atender alumnos con } \\
\text { TDAH }\end{array}$ \\
\hline
\end{tabular}

